\title{
Syngenite and gypsum minerals in aging equisetum arvense
}

Hwo-Shuenn Sheu ${ }^{1}$, Chung-Kai Chang ${ }^{1}$, Yu-Chun Chuang ${ }^{1}$, Yen-Chung Lai ${ }^{1}$

${ }^{1}$ National Synchrotron Radiation Research Center, Hsinchu, Taiwan E-mail: hsheu@nsrrc.org.tw

Equisetum arvense (horsetail grass) is one of the most ancient species known as living fossil plants which has long history and can be traced back to the age of dinosaurs. Equisetum arvense is also considered as one of the most important source of biogenic silica because of its ability of accumulating a great quantity of silica in all parts of the plant. Valentin Valtchev et al [1] reported the in situ zeolitization of a vegetal macrotemplate, induced by the biogenic silica of a fresh dry Equisetum arvense. Recently, Anna Sola-Rabada et al [2] report the isolation of a wide range of minerals from Equisetum arvense by a thermal treatment. As heat treatment, higher levels of minerals has been reported such as silica, calcium, $\mathrm{KCl}$, calcium sulphate and/or calcium silicates. A fresh and aging Equisetum arvense, which has been stored for two years in ambient condition, have been studied by Synchrotron powder X-ray diffraction (PXRD) method. No clear crystallite was found in fresh sample at room temperature, surprisingly, large amount of Syngenite ( $\mathrm{K} 2 \mathrm{Ca}(\mathrm{SO} 4) 2 \cdot 2 \mathrm{H} 2 \mathrm{O})$, Gypsum (CaSO4.H2O) and other minerals have appeared in aging sample but no silica crystalline materials was found. The in situ thermal treatment has been applied to investigate the crystals and their phase transitions by focusing the X-ray beam onto single stem. We will report the formation of minerals and their phase transformation in detail.

[1]. Valentin Valtchev, et al. (2003). Angew. Chem. Int. Ed. 42, $2782-2785$.

[2]. Anna Sola-Rabada, et al., (2016) J. Biol. Inorg. Chem. 21, 101-112.

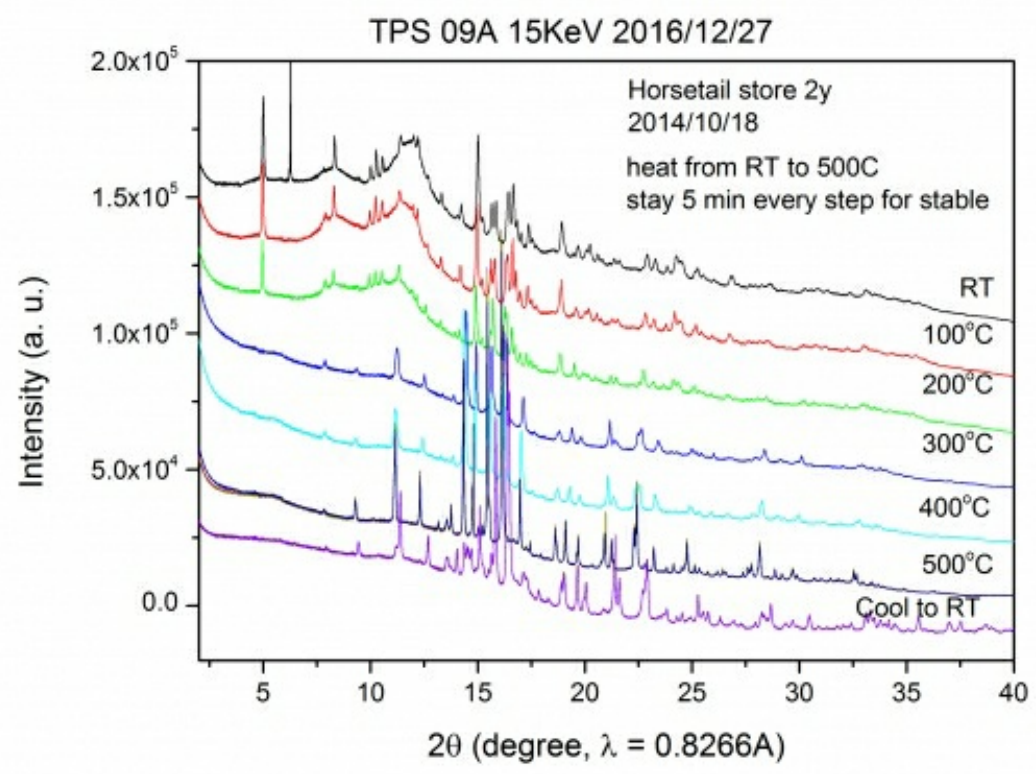

Keywords: Equisetum arvense, Syngenite and Gypsum, in situ Synchrotron PXRD 